\title{
Could Low Birth Weight be Associated with Cardiovascular Disease in Adolescence?
}

\section{Poderia o baixo peso ao nascimento ser associado com risco cardiovascular na adolescência?}

\author{
Priscila de Jesus dos Santos Alves ${ }^{1}$ Edward Araujo Júnior ${ }^{2}$ Ana Ciléia Pinto Teixeira Henriques ${ }^{1}$ \\ Francisco Herlânio Costa Carvalho ${ }^{3}$
}

${ }^{1}$ Department of Community Health, Escola de Medicina, Universidade Federal do Ceará, Fortaleza, CE, Brazil

2 Department of Obstetrics, Escola Paulista de Medicina, Universidade Federal de São Paulo, São Paulo, SP, Brazil

3 Department of Maternal and Child Health, Escola de Medicina,

Universidade Federal do Ceará, Fortaleza, CE, Brazil

\begin{abstract}
Address for correspondence Edward Araujo Júnior, MD, PhD, Rua Napoleão de Barros, 875, Vila Clementino, São Paulo, SP, Brazil 04024002 (e-mail: araujojred@terra.com.br).
\end{abstract}

Rev Bras Ginecol Obstet 2016;38:189-195.

\begin{abstract}
Keywords

- low birth weight

- cardiovascular disease risk factors

- anthropometry

- low socioeconomic status

- adolescence

Purpose Previous studies have shown that low birth weight (LBW) is associated with cardiovascular risk in late adulthood. Recent studies in adolescents suggest that modifiable factors may have greater influence on increased cardiovascular risk. This study aims to investigate the association between LBW and changes in anthropometric and biochemical risk factors during adolescence in a population with low average socioeconomic status.

Methods In a retrospective double cohort, data of birth weight were extracted from hospital records of children born on the same day between 1992 and 2002. According to the World Health Organization, we classified the children as having LBW or normal birth weight. A total of 172 subjects among children, adolescents and adults were researched. We measured anthropometric and clinical data, lipid profile and glucose after an overnight fasting. The low and normal weight groups were compared using Mann-Whitney U, Fischer exact, Chi-square $(\chi 2)$ and Student's t tests.

Results Pregnant women with preeclampsia delivered more newborns with LBW $(p<0.001)$. Anthropometric and clinical parameters were similar between groups. No differences were found in the family history of cardiovascular diseases $(p=0.1)$, family incomes $(p=0.8)$ and maternal school education $(p=0.8)$ between groups. Conclusion In this study, LBW did not increase cardiovascular disease risk factors in adolescents. We observed absence of association between low birth weight and poor health outcomes among adolescents with low socioeconomic status from an urban city in the Brazilian northeast.
\end{abstract}

received

October 27, 2015

accepted

January 8, 2016
DOI http://dx.doi.org/ 10.1055/s-0036-1583171. ISSN 0100-7203.
Copyright ( $\odot 2016$ by Thieme Publicações License terms Ltda, Rio de Janeiro, Brazil

() (1) $\odot \circledast$ 


\section{Resumo}

\author{
Palavras-chave \\ - baixo peso ao \\ nascimento \\ - risco cardiovascular \\ - antropometria \\ - baixo nível \\ socioeconômico \\ - adolescência
}

\begin{abstract}
Objetivo Estudos mostram que o baixo peso ao nascer está associado ao risco cardiovascular na idade adulta. Estudos recentes em adolescentes sugerem que fatores modificáveis podem ter grande influência no aumento do risco cardiovascular. Este estudo busca investigar a associação entre baixo peso ao nascer com mudanças nos fatores de risco antropométricos e bioquímicos durante a adolescência em uma população com baixo nível socioeconômico.

Métodos Em um estudo retrospectivo de coorte, dados de peso ao nascimento foram extraídos de registros de hospitais, de crianças que nasceram no mesmo dia, entre 1992 e 2002. De acordo com a Organização Mundial da Saúde, classificamos as crianças como baixo peso e peso normal. Um total de 172 pessoas, com idades entre 10 e 20 anos, foram pesquisadas. Avaliamos dados clínicos e antropométricos, perfil lipídico e glicemia de jejum. Os grupos de baixo peso e de peso normal foram comparados pelos testes de Mann-Whitney, Exato de Fisher, Qui-quadrado e t-Student.

Resultados Gestantes com pré-eclâmpsia tiveram mais partos de recém-nascidos com baixo peso $(p<0,001)$. Parâmetros clínicos e antropométricos foram similares em ambos os grupos. Não houve diferença na história familiar de doença cardiovascular $(p=0,1)$, renda familiar $(p=0,8)$ e nível educacional materno $(p=0,8)$ entre os grupos.

Conclusão Neste estudo, o baixo peso ao nascimento não aumentou o risco de doença cardiovascular na adolescência. Observou-se ausência de associação entre o baixo peso ao nascer e adversos resultados de saúde entre os adolescentes com baixo nível socioeconômico de um centro urbano no Nordeste brasileiro.
\end{abstract}

\section{Introduction}

Over the past two decades, an extensive and growing literature has investigated the associations between low birth weight (LBW) and chronic diseases. Several clinical studies demonstrate that LBW is an important risk factor for atherosclerosis, type 2 diabetes, hypertension, metabolic syndrome and endothelial dysfunction. ${ }^{1-8}$ Many of those studies were conducted in countries with high average socioeconomic status and the majority demonstrated a strong association between LBW and increased risk of cardiovascular disease.

Nevertheless, many other studies have only found a positive or a non-association between LBW and cardiovascular disease risk factors in young men and women or in children and adolescents. Moreover, there is convincing evidence that postnatal weight gain may have a greater influence on blood pressure than birth weight., ${ }^{4,9-11}$

There are not many studies of cardiovascular risk factors for LBW pediatric populations in the Brazilian northeast. ${ }^{12,13}$ This region has the lowest average socioeconomic status and the highest under-five mortality rates when compared with the other regions of the country. ${ }^{14}$ In recent years, the Brazilian government has invested heavily in programs in the northeast to ensure better child nutrition. However, these increases in the population's income have not been reflected in health indicators, and the prevalence of overweightness and obesity (important predictors for several cardiovascular disease risk factors) is rising. ${ }^{15}$

The hypothesis of this study is that LBW adolescents in low average socioeconomic status regions have the poorest health status. Thus, the research was conducted to investigate whether LBW is associated with changes during adolescence in anthropometric and biochemical risk factors, in a low average socioeconomic status population in the Brazilian northeast.

\section{Methods}

We conducted a retrospective cohort study with male and female participants with ages varying from 10 to 20 years, born from 1992 to 2002, with LBW (less than 2,500 g at birth) or normal birth weight (NBW) ( $\geq 2,500 \mathrm{~g}$ ) and who were born and lived in Fortaleza, Brazil. This study was approved by The Research Ethics Committee of the Assis Chateaubriand Maternity Teaching Hospital and conducted between February and August 2013. A similar sample size was applied in previous studies which assessed the endothelial and metabolic disorders and fetal growth restriction in adolescents. ${ }^{16,17}$

Hospital birth records were used to check perinatal conditions and select potential subjects. Eligibility criteria included being healthy at the moment of the evaluation and having no cardiovascular and/or endocrine conditions or relevant cardiovascular disease risk factors. Participants were contacted through personal visits, phone calls and letters.

A total of 101 LBW adolescents were located; however, the mothers of 15 of these adolescents refused to sign the consent for the adolescent's participation in the study. As for the NBW group, 102 adolescents were located, 
with the mothers of 16 of them refusing to sign the consent.

The evaluation consisted of an interview to investigate medical history and familial occurrence of cardiovascular disease risk factors, and to conduct laboratorial exams and anthropometric and clinical measurements.

Weight and total body fat percentage, with the participants wearing light clothes and no shoes, were measured to the nearest $0.1 \mathrm{~kg} / 0.1 \%$ using a calibrated model W835 body analyzer (Wanchai-Ho, China). A wall-mounted stadiometer Seca (model 206, Hamburg, Germany) to the nearest $0.1 \mathrm{~cm}$ was used to measure standing height. With these measurements the body mass index (BMI) was calculated (in kilograms per square meters) and evaluated according to age and gender, based on World Health Organization (WHO) references. ${ }^{18}$

An anthropometric tape measure Wiso (model T872) was used to measure the circumference of the waist, abdomen and hips. The measurements were taken at the end of a gentle expiration, with the reference point halfway between the lower rib and the top of the iliac crest; the umbilical scar and the largest point of the outer hip, respectively. Other two measurements were waist/hip ratio and biceps skinfold were also measured.

To measure blood pressure, a Microlife calibrated semi-automatic sphygmomanometer (model BP 3BTO-H, Dunedin, USA) was used, after a 30-minute rest, and giving a 1-minute interval between the two measurements. If the difference between the first and second measurements was $\geq 20 \mathrm{~mm} \mathrm{Hg}$, a new one would be taken, and the average of the two closest measurements was used as the final result. The Fourth Report on the Diagnosis, Evaluation, and Treatment of High Blood Pressure in Children and
Adolescents was used as a reference for blood pressure according to age and gender. ${ }^{19}$

For laboratorial evaluation, fasting blood sugar test samples were collected, as well as samples to measure total cholesterol, high-density lipoprotein cholesterol and triglycerides. Low density lipoprotein cholesterol was calculated when triglycerides $<400 \mathrm{mg} / \mathrm{dL}^{20}$ The I Guideline for Prevention of Atherosclerosis in Childhood and Adolescence was adopted as reference value. ${ }^{10}$ Each participant received their laboratory results and a cardiovascular report.

\section{Statistical Analysis}

Mean and standard deviations were calculated to all normality variables using Student's t test, and proportions were compared by Chi-square $\left(\chi^{2}\right)$ or Fisher exact tests. Kruskall-Wallis and Mann-Whitney $U$ tests were used for non-normal distribution variables and described as quartiles: first quartile (Q1), median (M) and third quartiles (Q3). Some variables were converted to Z-score by using the formula: ( $\mathrm{x}$ - mean)/standard deviation. Analysis were performed using Stata program (College Station, TX, USA) version 12.0 for Mac and statistically significant if $p<0.05$. An alpha error of $5 \%$ and a beta error of $20 \%$ were adopted to calculate the sample size according to a relative risk of 2.3 to hypertension in preterm and low birth weight subjects. $^{21}$

\section{Results}

Evaluations were obtained from 86 LBW and 86 NBW participants. The sample consisted of 56 females (65.1\%) in the

Table 1 Maternal characteristics during childbirth according offspring's birth weight

\begin{tabular}{|c|c|c|c|c|c|}
\hline & \multicolumn{2}{|c|}{$\begin{array}{l}\text { LBW } \\
\text { Q1 (M) Q3 }\end{array}$} & \multicolumn{2}{|c|}{$\begin{array}{l}\text { NBW } \\
\text { Q1 (M) Q3 }\end{array}$} & $p$ \\
\hline Age (years) & \multicolumn{2}{|c|}{$18.0(24.5) 30.0$} & \multicolumn{2}{|c|}{$20.0(23.0) 28.0$} & $0.5^{*}$ \\
\hline \multicolumn{6}{|l|}{ Pregnancy complications ( $n, \%)$} \\
\hline Preeclampsia & 32 & 37.2 & 23 & 26.7 & $<0.001 \dagger$ \\
\hline Diabetes & 2 & 2.3 & 0 & 0.0 & \\
\hline Other diseases & 43 & 49.9 & 13 & 15.2 & \\
\hline \multicolumn{6}{|l|}{ Mode of delivery $(\mathrm{n}, \%)$} \\
\hline Vaginal & 45 & 52.3 & 32 & 37.2 & $<0.05 \S$ \\
\hline Cesarean & 41 & 47.7 & 54 & 62.8 & \\
\hline Number of pregnancies & \multicolumn{2}{|c|}{$0.8 \pm 1.2$} & \multicolumn{2}{|c|}{$1.4 \pm 2.7$} & $0.2^{*}$ \\
\hline Number of births & \multicolumn{2}{|c|}{$0.6 \pm 0.9$} & \multicolumn{2}{|c|}{$0.9 \pm 1.8$} & $0.5^{*}$ \\
\hline Number of abortions & \multicolumn{2}{|c|}{$0.2 \pm 0.5$} & \multicolumn{2}{|c|}{$0.5 \pm 1.3$} & $0.3^{*}$ \\
\hline Complications in other pregnancies $(n, \%)$ & 22 & 25.6 & 20 & 23.3 & $0.4 \S$ \\
\hline Smoking (n,\%) & 2 & 2.4 & 8 & 9.6 & $0.1 \S$ \\
\hline
\end{tabular}

Abbreviations: LBW, low birth weight; M, median; NBW, normal birth weight; Q1, first quartile; Q3, third quartile.

Note: Values are median and interquartile range for continuous variables; number of participants and percentages are presented for categorical variables however.

*Mann-Whitney $\mathrm{U}$ test, ${ }^{\dagger}$ Fisher's exact, ${ }^{\S} \mathrm{Chi}-$ square $\left(\chi^{2}\right)$ test. 
Table 2 Perinatal, anthropometric, and clinical current data according to birth weight groups

\begin{tabular}{|c|c|c|c|c|c|}
\hline & \multicolumn{2}{|c|}{$\begin{array}{l}\text { LBW } \\
\text { Q1 (M) Q3 }\end{array}$} & \multicolumn{2}{|c|}{$\begin{array}{l}\text { NBW } \\
\text { Q1 (M) Q3 }\end{array}$} & $p$ \\
\hline \multicolumn{6}{|l|}{ Gender } \\
\hline Boys $(n, \%)$ & 30 & 34.9 & 34 & 39.5 & $0.5^{\dagger}$ \\
\hline Girls (n,\%) & 56 & 65.1 & 52 & 60.5 & \\
\hline SGA $(n, \%)$ & 49 & 57.0 & 9 & 10.5 & $<0.001^{\dagger}$ \\
\hline \multicolumn{6}{|l|}{ Current data } \\
\hline Age (years) & \multicolumn{2}{|c|}{$11.0(12.0) 14.0$} & \multicolumn{2}{|c|}{$11.0(13.0) 16.0$} & $0.2^{*}$ \\
\hline Weight $(\mathrm{kg})$ & \multicolumn{2}{|c|}{$40.2(47.7) 56.7$} & \multicolumn{2}{|c|}{$40.6(49) 58.5$} & $0.8^{*}$ \\
\hline Z-score weight & \multicolumn{2}{|c|}{$-0.01 \pm 1.0$} & \multicolumn{2}{|c|}{$0.01 \pm 1.0$} & $0.8^{\S}$ \\
\hline Height (m) & \multicolumn{2}{|c|}{$1.5(1.5) 1.6$} & \multicolumn{2}{|c|}{$1.5(1.6) 1.6$} & $0.1^{*}$ \\
\hline Z-score height & \multicolumn{2}{|c|}{$-0.1 \pm 1.0$} & \multicolumn{2}{|c|}{$0.1 \pm 1.0$} & $0.1^{\S}$ \\
\hline Abdominal circumference (m) & \multicolumn{2}{|c|}{$0.6(0.7) 0.8$} & \multicolumn{2}{|c|}{$0.6(0.7) 0.8$} & $0.6^{*}$ \\
\hline Z-score abdominal circumference & \multicolumn{2}{|c|}{$0.02 \pm 1.0$} & \multicolumn{2}{|c|}{$-0.02 \pm 1.0$} & $0.6^{\S}$ \\
\hline Hip circumference $(\mathrm{m})$ & \multicolumn{2}{|c|}{$0.6(0.7) 0.8$} & \multicolumn{2}{|c|}{$0.6(0.7) 0.7$} & $0.8^{\S}$ \\
\hline Z-score hip circumference & \multicolumn{2}{|c|}{$0.03 \pm 1.0$} & \multicolumn{2}{|c|}{$-0.03 \pm 1.0$} & $0.5^{\S}$ \\
\hline Waist/hip ratio & \multicolumn{2}{|c|}{$0.8(0.8) 0.8$} & \multicolumn{2}{|c|}{$0.7(0.8) 0.8$} & $0.2^{*}$ \\
\hline Z-score waist/hip ratio & \multicolumn{2}{|c|}{$0.1 \pm 0.1$} & \multicolumn{2}{|c|}{$-0.1 \pm 0.1$} & $0.1^{\S}$ \\
\hline BMI (mean) & \multicolumn{2}{|c|}{$17.6(20.1) 23.9$} & 17. & & $0.8^{*}$ \\
\hline Z-score BMI & & & -0.4 & & $0.5^{\S}$ \\
\hline Classification according to $\mathrm{BMI}$ & & & & & \\
\hline Overweightness/obesity (n,\%) & 23 & 26.8 & 23 & 26.8 & $0.5^{\dagger}$ \\
\hline Normal $(n, \%)$ & 54 & 62.8 & 55 & 64.0 & \\
\hline Body fat mass (\%) & 20.9 & & 20. & & $0.4^{*}$ \\
\hline Z-score body fat mass & 0.1 & & -0.1 & & $0.4^{\S}$ \\
\hline Biceps skinfold thickness (m) & 0.00 & 0.011 & 0.0 & 0.009 & $0.6^{*}$ \\
\hline Z-score biceps skinfold thickness & 0.05 & & -0.0 & & $0.6^{\S}$ \\
\hline $\mathrm{SBP}(\mathrm{mmHg})$ & 97( & & 90 & & $0.1^{*}$ \\
\hline Z-score SBP & 0.1 & & -0.1 & & $0.1^{\S}$ \\
\hline PAS $\geq 95^{\text {th }}$ percentile & 9 & 10.5 & 9 & 10.5 & $0.9^{\dagger}$ \\
\hline $\mathrm{DBP}(\mathrm{mmHg})$ & 60( & & 58 & & $0.1^{*}$ \\
\hline Z-score DBP & 0.1 & & -1.1 & & $0.1^{\S}$ \\
\hline $\mathrm{PAD} \geq 95^{\text {th }}$ percentile & 1 & 1.2 & 0 & 0 & $0.1^{\dagger}$ \\
\hline Family history of CVD $\int$ & & & & & \\
\hline Yes $(n, \%)$ & 83 & 96.5 & 78 & 90.7 & $0.1^{\dagger}$ \\
\hline No $(n, \%)$ & 3 & 3.5 & 8 & 9.3 & \\
\hline Menarche age & 11( & & 11 & & $0.2^{*}$ \\
\hline Familiar incomes (MW) & $1(1$ & & $1(1$ & & $0.8^{*}$ \\
\hline Maternal school education (years) & $5(8$ & & $5(8$ & & $0.8^{*}$ \\
\hline
\end{tabular}

Abbreviations: BMI, body mass index (in kilograms per square meters); CVD, cardiovascular disease; DBP, diastolic blood pressure; LBW, low birth weight; M, median; MW, minimum wage; NBW, normal birth weight; Q1, first quartile; Q3, third quartile; SBP, systolic blood pressure; SGA, small for gestation age.

Note: Values are median and interquartile range for continuous variables; number of participants and percentages are presented for categorical variables however.

${ }^{*}$ Mann-Whitney $\mathrm{U}$ test, ${ }^{\dagger}$ Chi-square test $\left(\chi^{2}\right)$ test, ${ }^{\S}$ Student's t-test. 
Table 3 Blood lipids and insulin profile according to birth weight groups

\begin{tabular}{|l|l|l|l|}
\hline & LBW & NBW & P $^{*}$ \\
\hline Glucose (mg/dL) & $79.7(9.6)$ & $82.3(9.5)$ & 0.2 \\
\hline TC (mg/dL) & $143.0(24.4)$ & $143.4(26.2)$ & 0.9 \\
\hline HDL-C (mg/dL) & $43.4(10.2)$ & $44.3(10.1)$ & 0.5 \\
\hline LDL-C (mg/dL) & $84.6(21.1)$ & $84.4(23.6)$ & 0.7 \\
\hline VLDL (mg/dL) & $14.6(6.5)$ & $13.9(7.1)$ & 0.4 \\
\hline TG (mg/dL) & $73.0(32.6)$ & $70.9(30.0)$ & 0.5 \\
\hline
\end{tabular}

Abbreviations: HDL-C, high-density lipoprotein cholesterol; LBW, low birth weight; LDL-C, low-density lipoprotein cholesterol; NBW, normal birth weight; TC, total cholesterol; TG, triglycerides; VLDL-C, very low-density lipoprotein cholesterol.

Note: Values are mean and standard variation.

*Mann-Whitney U test.

LBW group and 52 females (60.5\%) in the NBW group $(p=0.5)$, with an average age of 12.8 years for LBW $(\mathrm{SD}=2.2)$ and 13.6 years for NBW $(\mathrm{SD}=2.9)(p=0.2)$. Of the total of 58 adolescents born small for gestational age, 49 (57.0\%) were also LBW ( $p<0.05)$.

The maternal characteristics were similar, except for the mode of delivery $(p<0.05$ ) ( - Table 1 ). No significant differences were identified regarding age, gender distribution, or current anthropometric data (weight, height, abdominal circumference, BMI, classification according to BMI, body fat mass and biceps skinfold thickness) (-Table 2). The clinical parameters were similar between the groups. Systolic blood pressure and diastolic blood pressure levels were also similar in the LBW group (systolic blood pressure $=2.6$ $\mathrm{mm} \mathrm{Hg}$; diastolic blood pressure $=1.5 \mathrm{~mm} \mathrm{Hg}$ ). Subjects in the LBW group tended to have lower height $(p=0.1)$. No differences were found in the family history of cardiovascular diseases $(p=0.1)$, family incomes $(p=0.7)$ or maternal schooling $(p=0.8)$. We also expressed anthropometric variables as mean Z-scores. No significant differences were found. All the values were expressed as mean and standard deviations (-Table 2 ).

The data from the biochemical evaluation showed very similar results between LBW and NBW participants. Although low-density lipoprotein cholesterol, very low-density lipoprotein cholesterol and triglycerides levels were higher in the LBW group, there was no significant difference. Similarly, even though total cholesterol, high-density lipoprotein cholesterol and glucose levels were higher in the NBW group, no significant differences were observed (-Table 3).

Because more than $50 \%$ of the eligible patients were lost, we performed some statistical tests between participants and nonparticipants. LBW participants and non-participants had similar performances regarding perinatal characteristics such as maternal age $(p=0.4)$, number of maternal gestations and abortions ( $p=0.5 ; p=0.8$ respectively), maternal preeclampsia and diabetes ( $p=0.5 ; p=0.2$ respectively), age (the average age of participants was 13 , and the average age of non-participants was $12 ; p<0.05)$, gender $(p=0.7)$, prematurity $(p=0.1)$, small size for gestational age (higher frequency of adolescents born small for gestational age in the participant's group, $p<0.05$ ).

\section{Discussion}

The findings presented suggest that low birth weight was not associated with poor health outcomes among adolescents in the Brazilian northeast. The differences were non-significant for all risk factors except for blood pressure, where a borderline significant difference was observed. The adolescents in the LBW group had higher blood pressures $(2.6 \mathrm{~mm} \mathrm{Hg}$ for systolic blood pressure and $1.5 \mathrm{~mm} \mathrm{Hg}$ for diastolic blood pressure), and they tended to have lower height than adolescents in the NBW group. These three variables showed the highest difference in the anthropometric data and tended to be higher in the LBW group, but were not significant. Although we selected subjects born on the same day, from 1992 to 2002, the groups had a different quartile of age. This occurred because we couldn't localize the adolescents born exactly on the same day. However, this didn't affect the results.

One of the strongest predictors of hypertension in adulthood is a high level of blood pressure in childhood. ${ }^{22}$ Another important risk factor is gender, which may influence the probability of elevated blood pressure during adulthood. ${ }^{23}$ Among women, the risk ratio ranged from 2.6 to 5.7, while among men it ranged from 2.3 to 4.3 . However, some studies have found opposite results. A longitudinal prospective study with 250 subjects with ages between 11 and 14 years found no correlation between birth weight and blood pressure, weight or BMI. The authors suggested there are risk factors more important than LBW or gestational age that are related to increased blood pressure in childhood, such as high maternal BMI and a high birth weight (HBW). ${ }^{24}$

In Iceland, a study ${ }^{25}$ investigated 857 children with ages between 9 and 10 years, 51.9\% of which were girls. They found higher blood pressure levels among the boys, but no correlation was found between birth weight and absolute blood pressure values. Gestational age also did not correlate with blood pressure. Studies with other populations had 
similar results in the US, ${ }^{26}$ China, ${ }^{9}$ England, ${ }^{4}$ Italy $^{27}$ and Brazil. $^{28}$

Despite socioeconomic factors such as family incomes and maternal education being comparable, the LBW group did not have an increased risk of cardiovascular disease. Studies show that women who deliver LBW infants take meticulous care of them and pay closer attention to medical advices. ${ }^{29}$ This could be the reason for less cardiovascular disease risk factors associated with catch-up growth, ${ }^{3}$ a determinant factor for cardiovascular diseases in LBW newborns. On the other hand, Fortaleza currently ranks as the ninth worst Brazilian capital on the Municipal Human Development Index. ${ }^{30}$ This index encompasses longevity, education and income. Thus, in this study NBW newborns were also exposed to poor conditions, which may explain why their results were similar to those of LBW newborns, even though the groups had a similar family history of cardiovascular diseases.

Countries have some peculiarities regarding socioeconomic status. It has been estimated that in regions in the world with low average socioeconomic status more than 200 million children less than 5 years old are not fulfilling their development potential. This fact can be the result of poverty, nutritional deficiencies and inadequate learning opportunities. ${ }^{31}$ In Brazil specifically, there have been fast changes in major social health determinants and in the organization of health services over the past three decades. The main changes during this period were economic growth, reduction in income inequality, urbanization, improvements in the education of women, decreased fertility rates, a government cash transfer program and improvements in the provision of water and sanitation. ${ }^{32}$

Furthermore, since the 1970's a nutritional transition is occurring in Brazil, involving a decline in malnutrition in children and an increase in obesity and overweightness in adults. It is an apparent paradox that the highest frequencies of normal anthropometric measurements in Brazilian adults were found in the poorer northern and northeastern regions of Brazil. ${ }^{33}$ However, a recent study showed that cardiovascular disease increased in these regions. ${ }^{34}$

The results contribute toward testing the validity of the Barker hypothesis in countries with low average socioeconomic status, especially in the poorest region of Brazil. An important feature in this study is that socioeconomic status and the same day of birth were accounted for and the groups were similar in average chronological age, gender and time frame for the menarche. We used international parameters to facilitate future comparisons with our data.

Some study limitations need to be addressed. Firstly, the neonatal data obtained from the hospital records had only been collected prior to the present study for other purposes and a long time ago. For that reason, some data was missing. Secondly, adolescents with birth weight between 2,500 and $3,000 \mathrm{~g}(n=25)$ were included in the NBW group; however, this group could include some subjects who did not reach their potential for intrauterine growth, which lead to confusing results. Although some authors categorized birth weight in a manner similar to this research, they had different results. ${ }^{35}$ Thirdly, complete information regarding pubertal status was not available, so bias may have been introduced by giving all participants the same pubertal status. Fourthly, we can't increase our sample. As we have described, there were some difficulties in obtaining the hospital records that have maternal and neonatal data. Despite this, we got more than one thousand records. Unfortunately, we were unable find most of the patients. However, as we have shown, participants and non-participants had similar characteristics, and non-participants were not the reason behind the few differences between the groups that we found. Fifthly, we based our sample size calculation on hypertension; however a few number of subjects had high levels of blood pressure. This could be the reason why no other differences were found.

Summarizing, LBW did not increase cardiovascular disease risk factors in young adults in the second decade of life. The absence of an association between LBW and poor health outcomes among adolescents in a low average socioeconomic status population from a capital in the Brazilian northeast corroborates previous findings in other countries with low average socioeconomic status. We suggest future prospective studies with more subjects to investigate this association.

\section{References}

1 Barker DJ. The fetal origins of coronary heart disease. Acta Paediatr Suppl 1997;422:78-82

2 Kark M, Tynelius P, Rasmussen F. Associations between birth weight and weight change during infancy and later childhood, and systolic blood pressure at age 15 years: the COMPASS study. Paediatr Perinat Epidemiol 2009;23(3):245-253

3 Morrison JL, Duffield JA, Muhlhausler BS, Gentili S, McMillen IC. Fetal growth restriction, catch-up growth and the early origins of insulin resistance and visceral obesity. Pediatr Nephrol 2010; 25(4):669-677

4 Primatesta P, Falaschetti E, Poulter NR. Birth weight and blood pressure in childhood: results from the Health Survey for England. Hypertension 2005;45(1):75-79

5 Xiao X, Zhang ZX, Li WH, et al. Low birth weight is associated with components of the metabolic syndrome. Metabolism 2010;59(9): 1282-1286

6 Cosmi E, Visentin S, Fanelli T, Mautone AJ, Zanardo V. Aortic intima media thickness in fetuses and children with intrauterine growth restriction. Obstet Gynecol 2009;114(5):1109-1114

7 Zanardo V, Visentin S, Trevisanuto D, Bertin M, Cavallin F, Cosmi E. Fetal aortic wall thickness: a marker of hypertension in IUGR children? Hypertens Res 2013;36(5):440-443

8 Zanardo V, Fanelli T, Weiner G, et al. Intrauterine growth restriction is associated with persistent aortic wall thickening and glomerular proteinuria during infancy. Kidney Int 2011;80(1): 119-123

9 Bowers K, Liu G, Wang P, et al. Birth weight, postnatal weight change, and risk for high blood pressure among Chinese children. Pediatrics 2011;127(5):e1272-e1279

10 Back Giuliano IdeC, Caramelli B, Pellanda L, Duncan B, Mattos S, Fonseca FH; Sociedade Brasileira de Cardiologia. I guidelines of prevention of atherosclerosis in childhood and adolescence. Arq Bras Cardiol 2005;85(Suppl 6):4-36 
11 Visentin S, Grumolato F, Nardelli GB, Di Camillo B, Grisan E, Cosmi E. Early origins of adult disease: low birth weight and vascular remodeling. Atherosclerosis 2014;237(2):391-399

12 Salgado CM, Jardim PC, Teles FB, Nunes MC. Low birth weight as a marker of changes in ambulatory blood pressure monitoring. Arq Bras Cardiol 2009;92(2):107-121

13 Sousa MA, Guimarães IC, Daltro C, Guimarães AC. Association between birth weight and cardiovascular risk factors in adolescents. Arq Bras Cardiol 2013;101(1):9-17

14 Instituto Brasileiro de Geografia e Estatística (IBGE) [Internet]. Tábuas abreviadas de mortalidade por sexo e idade: Brasil, Grandes Regiões e Unidades da Federação 2010. Rio de Janeiro: IBGE; 2013 [citado 2013 Set 22]. Disponível em: http://biblioteca. ibge.gov.br/visualizacao/livros/liv65137.pdf

15 Batista Filho M, Rissin A. [Nutritional transition in Brazil: geographic and temporal trends]. Cad Saude Publica 2003;19 (Suppl 1):S181-S191 Portuguese

16 dos Santos Alves PdeJ, P. T Henriques AC, Pinto LRM, et al. Endothelial and metabolic disorders in adolescence: low birth weight is not an isolated risk factor. J Pediatr Endocrinol Metab 2015;28(3-4):407-413

17 Alves PJ, Henriques AC, Silva KF, et al. The influence of fetal growth restriction on cardiovascular health among adolescents in Brazil: a retrospective cohort study. Indian Pediatr 2015;52(2):109-114

18 de Onis M, Onyango AW, Borghi E, Siyam A, Nishida C, Siekmann J. Development of a WHO growth reference for school-aged children and adolescents. Bull World Health Organ 2007;85(9): 660-667

19 National High Blood Pressure Education Program Working Group on High Blood Pressure in Children and Adolescents. The fourth report on the diagnosis, evaluation, and treatment of high blood pressure in children and adolescents. Pediatrics 2004;114(2, Suppl 4th Report)555-576

20 Friedewald WT, Levy RI, Fredrickson DS. Estimation of the concentration of low-density lipoprotein cholesterol in plasma, without use of the preparative ultracentrifuge. Clin Chem 1972; 18(6):499-502

21 de Jong F, Monuteaux MC, van Elburg RM, Gillman MW, Belfort MB. Systematic review and meta-analysis of preterm birth and later systolic blood pressure. Hypertension 2012;59(2):226-234

22 Cook NR, Gillman MW, Rosner BA, Taylor JO, Hennekens CH. Prediction of young adult blood pressure from childhood blood pressure, height, and weight. J Clin Epidemiol 1997;50(5): $571-579$
23 Carrico RJ, Sun SS, Sima AP, Rosner B. The predictive value of childhood blood pressure values for adult elevated blood pressure. Open J Pediatr 2013;3(2):116-126

24 Filler G, Yasin A, Kesarwani P, Garg AX, Lindsay R, Sharma AP. Big mother or small baby: which predicts hypertension? J Clin Hypertens (Greenwich) 2011;13(1):35-41

25 Steinthorsdottir SD, Eliasdottir SB, Indridason OS, Palsson R, Edvardsson VO. The relationship between birth weight and blood pressure in childhood: a population-based study. Am J Hypertens 2013;26(1):76-82

26 Falkner B, Hulman S, Kushner H. Effect of birth weight on blood pressure and body size in early adolescence. Hypertension 2004; 43(2):203-207

27 Salvi P, Meriem C, Temmar M, et al. Association of current weight and birth weight with blood pressure levels in Saharan and European teenager populations. Am J Hypertens 2010;23(4):379-386

28 Menezes AM, Hallal PC, Horta BL, et al. Size at birth and blood pressure in early adolescence: a prospective birth cohort study. Am J Epidemiol 2007;165(6):611-616

29 Freitas Md, Kernkraut AM, Guerrero SM, et al. Followup of premature children with high risk for growth and development delay: a multiprofessional assessment. Einstein (Sao Paulo) 2010; 8(2):180-186

30 Programa das Nações Unidas para o Desenvolvimento. Instituto de Pesquisa Econômica Aplicada. Fundação João Pinheiro [Internet]. Índice de Desenvolvimento Humano Municipal: ranking todo o Brasil 2010. 2013 [citado 2013 Oct 15]. Disponível em: http://www.atlasbrasil.org.br/2013/pt/ranking/

31 Walker SP, Wachs TD, Grantham-McGregor S, et al. Inequality in early childhood: risk and protective factors for early child development. Lancet 2011;378(9799):1325-1338

32 Victora CG, Aquino EM, do Carmo Leal M, Monteiro CA, Barros FC, Szwarcwald CL. Maternal and child health in Brazil: progress and challenges. Lancet 2011;377(9780):1863-1876

33 Batista Filho M, Miglioli TC, Santos MC. Anthropometric normality in adults: the geographical and socio-economic paradox of the nutritional transition in Brazil. Rev Bras Saude Mater Infant 2007; 7(4):487-493

34 Baena CP, Chowdhury R, Schio NA, et al. Ischaemic heart disease deaths in Brazil: current trends, regional disparities and future projections. Heart 2013;99(18):1359-1364

35 Monteiro PO, Victora CG, Barros FC, Monteiro LM. Birth size, early childhood growth, and adolescent obesity in a Brazilian birth cohort. Int J Obes Relat Metab Disord 2003;27(10):1274-1282 